\title{
Relative Versus Fundamental Valuation: An Empirical Study of US Biotechnology Firms Around the 2000 High-Tech Bubble
}

\author{
Dzung Viet Nguyen ${ }^{1}$ \\ ${ }^{1}$ Faculty of Banking and Finance, Foreign Trade University, Hanoi, Vietnam \\ Correspondence: Dzung Viet Nguyen, Faculty of Banking and Finance, Foreign Trade University, 91 Chua Lang, \\ Hanoi, Vietnam.
}

Received: August 28, 2020

Accepted: November 4, 2020

Online Published: December 6, 2020

doi:10.5430/ijfr.v11n6p226

URL: https://doi.org/10.5430/ijfr.v11n6p226

\begin{abstract}
This study is related to the issue of whether the stock market reflects the fundamental value of high-tech firms around the 2000 high-tech bubble. We extend the literature on firm valuation by exploiting the conceptual difference between intrinsic and relative values. We apply the residual income model and valuation multiples to estimate these two values respectively and make a comparison for a sample of biotechnology firms. Under realistic assumptions, it seems that estimated fundamental values of these firms fail to be reflected by the stock market. Their market valuation is rather based on relative value for both periods before and after the fall of high-tech stocks.
\end{abstract}

Keywords: intrinsic value, relative value, residual income model, valuation multiples, biotechnology firms

\section{Introduction}

Information needed to value a company comes from three main sources: (i) its past record and current financial statements, (ii) forecasts and (iii) comparable firms and/or competitors. While the first two information sources related to financial characteristics of a company are required for estimating its intrinsic value, the third is used to provide a relative valuation. The intrinsic value of a company is the present value of cash flows that the company is expected to generate in the future, based on information currently available. This value depends on the company's ability to generate future cash flows and risk associated with them. The method used to estimate intrinsic value is also called method of discounted cash flows. While this method provides a theoretical basis for estimating intrinsic value and on which other valuation approaches rely, the relative evaluation plays an important role in practice. In a relative evaluation, the goal is not to find intrinsic value but to measure an asset based on the valuation of similar assets by the market.

Damodaran (2001) cites three reasons why the relative approach is widespread in the practice of business valuation. First, at technical level, a valuation based on multiples and comparable firms are done with fewer assumptions and more rapidly than a discounting model. Second, it is easier to understand and to present to clients. Finally, it is able to reflect market trends since the estimate of a firm's value is based on the valuation of other firms by the market. For example, in a market where Internet companies are overvalued, the value given by a relative valuation to an Internet firm tends to be higher than that achieved by a fundamental valuation.

Practical advantages of the relative valuation approach sometimes hide its drawbacks at theoretical level. Firstly, the ease with which a relative valuation is made may also lead to estimates of value that do not reflect key variables such as risk and growth. Then, since the approach allows to reflect market trends, a share of stock may be overvalued (undervalued) based on a model of discounted cash flows but undervalued (overvalued) with a relative valuation if comparables used are all overvalued (undervalued) by the market. Given this conceptual difference, what can be said about the place of these two valuation approaches in valuing new high-tech firms?

What value, fundamental or relative, does the market rely on to value firms? Answers to this question can be found by analyzing information sources used for valuation. For some companies, three sources of information mentioned above for valuation purpose can be complementary but for others, they may be substitutes for one another, i.e. a more readily available type of information can be substituted for an unavailable one. For example, the fact that a large U.S. automaker has a long history can offset a very small number of its comparable companies. On the other hand, a still very young firm that has little interest to financial analysts can be in an area where comparable firms are numerous. 
Investors face many information problems when valuing new high-tech firms. These firms are in early stages of their life cycle and often make very important intangible investments. Their past and their financial statements are of little help for valuation purpose because they do not contain much information about future growth, a key determinant of their value. In addition, the number of analysts who follow them is often very modest. The first two sources are not rich in information, the third can play an important role. According to Damodaran (2001), given these information problems, it is highly likely that investors base their valuation of these companies on a relative rather than fundamental approach. The value of such a company can be strongly influenced by the way comparable firms are valued by the market, particularly in areas where contagion effect is important. This argument is supported by Huberman \& Regev (2001). The authors note that no new information on the potential of a drug to treat cancer led to a dramatic increase in market value of EntreMed, a U.S. biotech company owning its property right. This increase was contagious as other biotechnology values, particularly firms comparable to EntreMed, reacted similarly. These reactions, however, contrast with those that occurred five months earlier and seven months later when new information was revealed: the change in value of EntreMed was minimal and there was almost no contagion. This study suggests that market value may vary depending on non-fundamental factors and these variations are concentrated in firms that have something in common.

\section{Previous Studies Using Methods of Fundamental and Relative Valuation}

It seems that the researchers' effort to address the practical problem of measuring intrinsic value is still modest given its important role in financial theory. According to Lee et al. (1999), the lack of attention to this subject reflects the standard academic point of view that considers market value as the best estimate of intrinsic value. The authors claim that the equality market value / intrinsic value is based on the assumption that arbitrage costs are not significant. When information and transaction costs are negligible, securities can be ordered and delivered to the point at which their price fully reflects their intrinsic value. However, when these costs become significant and/or intrinsic value is difficult to measure, market value does not fully reflect intrinsic value and adjusting the former to the latter takes time. Once the possibility of divergence between market value and intrinsic value is accepted, estimating the latter becomes a crucial issue.

Kaplan \& Ruback (1995) test the method of discounted cash flows in the context of highly leveraged transactions. They compare market value of these transactions with their value obtained by discounting expected cash flows at cost of capital given by CAPM. They show that these two values are very close. The success of this method despite the transactions' debt level and complexity raises the question of whether expected cash flows are not adjusted in order to justify transactions' prices. Indeed, cash flows can be adjusted upward when their true expected value is below the level necessary to obtain financing resources. A downward adjustment may occur otherwise, e.g. when there is a requirement for managers of companies involved in these transactions to obtain investment banks' view that transactions price is correct. The authors find little evidence of such adjustments and conclude that the discounted cash flow method can provide reliable estimates of market value. Gilson et al. (2000) use a similar approach to value bankrupt firms. They also show that it gives an unbiased estimate of market value but valuation errors' variation is significant. Their sensitivity analysis shows that this dispersion cannot be entirely attributed to errors in model assumptions related to cost of capital or long-term growth rate. They indicate that valuation errors may be due to a lack of information on these firms. They also find that these errors are caused by the incentive to bias cash flows from financial backers involved in the process of bankruptcy and corporate reorganization.

A number of academic researchers implement the residual income model for empirically estimating intrinsic value. Penman \& Sougiannis (1998) compare this model with DDM and DCF. These three models are equivalent with infinite forecast horizon. However, to facilitate their empirical application, a finite horizon and a terminal value must be specified. Using historical data to proxy for ex ante expected values, Penman \& Sougiannis (1998) show that for a finite horizon, the residual income model provides estimates closer to market values than the other two methods. Based on a sample of listed Australian firms, Wells et al. (2008) indicate that the residual income model provides better estimates of firm value than cash-flow and dividend models. Jorgensen et al. (2011) compare the valuation accuracy of the equity value estimates inferred from empirical implementations of the abnormal earnings growth model (Ohlson \& Juettner-Nauroth, 2005; the OJ estimates) with the residual income model (Ohlson, 1995; the RIV estimates) and find that the OJ estimates generally underperform the RIV estimates. Higgins (2011) implements the basic residual income model with one term of abnormal earnings to forecast stock price and shows how to address autocorrelation to improve forecast accuracy. Based on a sample of SP500 firms, this approach results in a quite low mean absolute percentage error. Kuo (2017) develops a methodology to incorporate industry and firm-specific factors into the residual income model. This method provides neglected valuation information when analysts' earnings forecasts are used and the results suggest that it improves the accuracy of stock value forecasting. 
The applicability of the residual income model has brought about a new line of research trying to empirically show that a better estimate of fundamental value allows to better predict future stock returns. Frankel \& Lee (1998) use this model with earnings forecasts from $\mathrm{I} / \mathrm{B} / \mathrm{E} / \mathrm{S}$ to estimate intrinsic value $(\mathrm{V})$ of U.S. companies. They find that estimated values explains $70 \%$ of changes in stock prices $(\mathrm{P})$ and the ratio $\mathrm{V} / \mathrm{P}$ allows to better predict future returns than book-to-market and size. Frankel \& Lee (1996) provide very similar results in an international context. Dechow et al. (1999) implement the residual income model with Ohlson (1995)'s information dynamics. They also show that the ratio V/P helps predicting future returns. In these studies, stocks with higher (lower) ratios V/P have higher (lower) future returns, especially for investment horizons of three to five years. Lee et al. (1999) and Lee \& Swaminathan (1999) study intrinsic value of companies that make up the Dow Jones with this model. They model the relationship between estimated intrinsic values and market values as a cointegration system. In other words, these two values converge steadily towards the true (but unobservable) fundamental value in the long run. They show that in this framework, a better estimate of fundamental value is not only correlated with observed values on the market but also helps to better predict long-term stock returns. They observe that the ratio V/P has a more stationary average, a lower standard deviation, a higher mean-reversion rate and especially a better ability to predict future returns than traditional indicators such as ratios B/P, E/P and D/P. Lee et al. (2013) also find that market value is fractional cointegrated with book value and residual income. This implies that the long-run relationship follows a slow but mean-reverting process. Their results therefore support the Ohlson (1995) residual income model.

In valuation practice, an alternative to a basic and theoretically sophisticated model is to estimate a firm's relative value based on comparable firms. This practical approach is also the subject of a number of research works. Alford (1992) studies the impact of selecting comparable firms on the P/E ratio-based valuation method. Results indicate that an industry-based selection is most effective and that this impact is greater for large than for small firms. Kaplan \& Ruback (1995) and Gilson et al. (2000) find that a valuation method based on comparables have the same degree of accuracy as DCF. Kim \& Ritter (1999) examine the relative method's role in IPOs valuation. Their results show that the inclusion of forecasts in estimating multiples and the control for differences in profitability and growth among firms give a better valuation than only using historical data. Liu et al. (2002) and Lie \& Lie (2002) extend such studies to examine a larger number of multiples with much larger samples of U.S. listed firms. In Liu et al. (2002), valuation is more accurate with multiples based on earnings forecasts. Particularly, they find that the relative method provides estimates closer to market values than those obtained from the residual income model. In terms of relative performance, valuation multiples are ranked in the following descending order for all industries: multiple of forecasted earnings (P/fE), multiple of historical earnings $(\mathrm{P} / \mathrm{E})$, multiple of cash flows $(\mathrm{P} / \mathrm{C})$, multiple of book value (P/B) and multiple of sales (P/S). The ranking in Lie \& Lie (2002) is not the same: P/B, P/fE, P/C, P/E and P/S. They also show that this relative method's accuracy varies considerably with firm size, profitability and intensity of intangible investment.

The importance of comparables in valuation is also indicated by some studies on the contagion effect in which an announcement made by one firm influences its value and also has an impact on other firms (comparables/ competitors). For example, Lang \& Stulz (1992) show that bankruptcy announcements lower the value of announcing firms and that of their competitors. As comparables are widespreadly used in firm valuation and a contagion effect exists, Eberhart (2001) argues that they contain a significant amount of information that investors use in securities valuation. To confirm this idea, he tests and finds a significant negative relationship between market reaction during an earnings announcement of a firm - a proxy for the degree of information asymmetry - and the number of comparables to this firm.

This review of related studies indicates that most of them assume a correct valuation by the market and take market value as a benchmark to judge the valuation performance of used methods. For example, Kaplan \& Ruback (1995) conclude that the discounted cash flows method they use is reliable for estimating market values. Liu et al. (2002) find that a theoretically more sophisticated fundamental valuation model is less efficient than the approach based on some multiples. Assuming that market valuation is correct, they even describe this result as "surprising". There have also been some studies relaxing the above assumption and accepting the possibility that market valuation can be incorrect, but they only focus on fundamental value. In what follows, we conduct an empirical study that complements this literature in two ways. Conceptually, we exploit the difference between intrinsic and relative values by comparing them directly to get an idea of firm valuation by the market. In term of application field, we examine this issue for new high-tech firms. This allows us to highlight the role of these two types of value in the case of these companies. In the next sections, we discuss the methodology, sample and data collection. 


\section{Methodology}

\subsection{Fundamental Value Estimates}

In this study, the residual income model is used to estimate intrinsic value.

$$
\hat{P}_{t}=b_{t}+\sum_{\tau=1}^{\infty} \frac{E_{t}\left(x_{t+\tau}^{a}\right)}{\left(1+k_{e}\right)^{\tau}}
$$

Where:

$\hat{P}_{t}$ : estimated intrinsic value of a share of stock at $\mathrm{t}$

$x_{t+\tau}^{a}$ : expected residual earnings per share at $\mathrm{t}+\tau\left(x_{t+\tau}^{a}=x_{t+\tau}-k_{e} \times b_{t+\tau-1}\right)$

$x_{t+\tau}$ : expected earnings per share at $\mathrm{t}+\tau$

$b_{t}$ : book value per share at $\mathrm{t}$

$k_{e}:$ cost of equity capital

$E_{t}$ : Expectation based on information available at $\mathrm{t}$

The model expresses stock value in terms of book value and an infinite series of abnormal earnings. To apply this model empirically, a forecast horizon, assumptions for estimating terminal value and proxies for investors' expectation must be specified. We follow Lee et al. (1999) who rewrite the equation (1) as follows:

$$
\hat{P}_{t}=b_{t}+\sum_{\tau=1}^{\infty} \frac{E_{t}\left[\left(R O E_{t+\tau}-k_{e}\right) \times b_{t+\tau}\right]}{\left(1+k_{e}\right)^{\tau}}
$$

Where $R O E_{t+\tau}$ is expected return on equity for $\mathrm{t}+\tau$.

Implementing the residual income model requires to estimate the following variables: expected book values of equity (b) expected returns on equity $(R O E)$ and cost of equity $\left(k_{e}\right)$. To proxy for investors' expectation, we take, following Lee et al. (1999), forecasts provided by financial analysts. In finance, historical data is often used to proxy for expectation vis-à-vis a variable. This estimate is very imperfect because what happened previously may not occur in the future. The availability of financial analysts' forecasts provides an alternative that can improve the quality of these proxies. These forecasts incorporate information on the future that is not captured by historical data. Several studies show that financial analysts' forecasts are more accurate than statistical models fed by past accounting data (Note 1). Analysts have informational and temporal advantages over statistical models. Indeed, if the predictive ability of deterministic models relies on time series, that of financial analysts integrates information from other sources of forecasts. Furthermore, while data used in deterministic models is distributed discretely (quarterly, annually ....), financial analysts receive continuous information (forecasts by managers, briefings, interviews...) which allows them to be more responsive in their forecast revisions.

Based on the clean surplus relation, expected book values of equity are estimated as follows:

$$
b_{t+1}=b_{t}+(1-d) \times x_{t+1}
$$

Where:

$b_{t}$ and $b_{t+1}$ : book values per share for periods $\mathrm{t}$ and $\mathrm{t}+1$ respectively

$x_{t+1}$ : forecasted earnings per share for period $\mathrm{t}+1$

$d$ : dividend payout ratio that is estimated using accounting data of the most recent fiscal year before valuation date.

Based on earnings forecasts and expected book values, expected returns on equity can be calculated:

$$
R O E_{t+1}=\frac{x_{t+1}}{b_{t}}
$$

CAPM is used to estimate cost of equity capital.

Finally, a forecast horizon and a terminal value are needed to estimate intrinsic value from the model. The use of forecast horizons in previous studies shows a certain diversity. Lee et al. (1999) use three alternative horizons: 3, 12, 
and 18 years. Beyond the explicit forecast period of financial analysts, the authors implicitly predict future returns on equity by linearly linking rates provided by analysts and estimated from historical data. In theory, this horizon should be long for companies to achieve their competitive balance. However, the ability to predict future performance decreases rapidly over time and more errors are incorporated into long expansions. The horizons used by Frankel \& Lee (1998) are much shorter: 2 and 3 years. In this study, we do not use forecast horizons as long as 12 and 18 years since estimates are less accurate over time. We use horizons coinciding with forecasts periods of financial analysts, which are 2 to 4 years in our data.

From equation (2) and earnings forecasts, we estimate intrinsic value as follows:

$$
\hat{P}_{t}=b_{t}+\sum_{i=1}^{n-1} \frac{\left(R O E_{t+i}-k_{e}\right)}{\left(1+k_{e}\right)^{i}} \times b_{t+i-1}+\frac{\left(R O E_{t+n}-k_{e}\right)}{\left(1+k_{e}\right)^{n-1} \times k_{e}} \times b_{t+n-1}
$$

$n$ is the furthest year in analysts' forecast periods. We follow Frankel \& Lee (1998) and Lee et al. (1999) who assume that the residual income of year $n$ is perpetual.

\subsection{Relative Value Estimates}

In the relative valuation approach, a firm is valued based on market valuation of comparable companies. This approach involves applying a valuation multiple derived from comparables to a firm's corresponding value driver in order to estimate its value.

$$
\hat{P}_{i, t}=V C_{i, \tau} \times M_{j \in \psi_{i}}\left\{\frac{P_{j, t}}{V C_{j, \tau}}\right\}
$$

Where:

$\mathrm{i}$ indicates the company to be valued and $\mathrm{j}$ indicates comparable firms

$\hat{P}_{i, t}$ : estimated value of firm i's share of stock at time $\mathrm{t}$

$V C_{i, \tau}$ : value driver of firm i

$P_{j, t}:$ share price of comparable firm $\mathrm{j}$ at time $\mathrm{t}$

$V C_{j, \tau}$ : value driver of comparable firm $\mathrm{j}$

$\frac{P_{j, t}}{V C_{j, \tau}}$ : valuation multiple of comparable firm $\mathrm{j}$ at time $\mathrm{t}$

$M$ : mean or median calculated from the set $\psi$ of firm i's comparables.

The relative valuation based on comparable has two components: computing valuation multiples and selecting a sample of comparables.

\subsubsection{Valuation Multiples}

We examine two valuation multiples that are among the most used in practice: $\mathrm{P} / \mathrm{B}$ and $\mathrm{P} / \mathrm{S}$ (formulas of which are shown in Table 1). We do not use multiples of historical and forecasted earnings since their values are often negative in our sample of high-tech firms.

Table 1. Valuation multiples

\begin{tabular}{ll}
\hline Multiple & Definition \\
\hline Multiple of book value $(P / B)$ & Market capitalization / Book value of equity \\
\hline Multiple of sales $(P / S)$ & $\begin{array}{l}\text { (Market capitalization + Book value of long-term } \\
\text { debt) / Net sales }\end{array}$ \\
\hline
\end{tabular}




\subsubsection{Selection of Comparable Firms}

A comparable company is similar to the firm to be valued in terms of cash flows, growth potential and risk. The relative valuation approach would be even simpler if each firm to be valued had at least one identical listed company. However, finding a company that strictly resembles another is impossible. In practice, financial analysts define comparable firms as those in a same industry as the company to be valued. The implicit assumption here is that companies in a same industry have similar growth and risk characteristics. Alford (1992) shows that a valuation using multiples is more reliable when comparables are selected based on 2 or 3-digit SIC codes. He also notes that changes in P/E multiples explained by risk and profit growth are also explained by industry dummies. In Liu et al. (2002), valuation errors decrease when comparables are selected on an industrial basis rather than from the entire sample.

We rely on two-digit industrial codes as classified by the FTSE International Classification System available in Datastream to select comparable firms.

\section{Sample and Data}

My initial sample is based on the final sample of Ely et al. (2003). It includes 83 biotech firms whose phases of drugs development are subjected to investigations conducted by the American Association of Pharmaceutical Manufacturers (PhRMA) during the period 1988-1998. We retain these 83 biotech companies as our initial sample and extend the study period until 2002 to examine the possible difference in valuation for two sub-periods separated by the fall of high-tech values in 2000. Specifically, three financial years 2000, 2001 and 2002 are added to the study period.

Table 2. Data sources and sample size

\begin{tabular}{llll}
\hline Data source & Data type & $\begin{array}{l}\text { Number } \\
\text { firms }\end{array}$ & $\begin{array}{l}\text { of } \\
\text { observations }\end{array}$ \\
\hline $\begin{array}{l}\text { Datastream } \\
\text { (Market data) }\end{array}$ & $\begin{array}{l}\text { Stock prices, risk free interest rate, S\&P 500 } \\
\text { index }\end{array}$ & 69 & 473 \\
\hline $\begin{array}{l}\text { Datastream } \\
\text { (Accounting data) }\end{array}$ & $\begin{array}{l}\text { Book value of equity per share, sales per } \\
\text { share }\end{array}$ & 61 & 402 \\
\hline I/B/E/S & Earnings forecasts & 39 & 214 \\
\hline
\end{tabular}

Table 2 presents the data types required for this study, their sources and the variation in sample size due to data availability. Two data sources are used to estimate intrinsic and relative values. Earnings forecasts are provided by the database I/B/E/S of Thomson Financial. Accounting data (book value of equity per share, sales per share, dividend payout ratio) and market data (stock prices, S \& P 500 index, risk-free interest rate) are extracted from Datastream. Beta coefficients are estimated using the conventional market model with historical weekly stock and index returns for a three-year period preceding the valuation date. Weekly differences between the S\&P 500 index returns and risk-free rates (3-month Treasury bills) are averaged over the period of 1980 to valuation dates to estimate risk premiums.

\section{Empirical Results}

We use the equation (3) to estimate a stock's intrinsic value and compare with its price recorded three months after the financial year end. For relative valuation, we first select companies comparable to the firm to be valued using the biotechnology sector 2-digit code as classified by the FTSE International Classification System available in Datastream. We then compute the median value for this ratio: Market value recorded three months after the financial year end / value driver of this financial year. For each firm, we estimate the intrinsic value of a share of stock by multiplying this median value by the firm's value driver.

Table 3 presents some descriptive statistics of estimated values. The average cost of equity capital is $15 \%$. The average of intrinsic values is far below that of stock prices. Prices are much closer to estimated relative values. 
Table 3. Descriptive statistics

\begin{tabular}{llll}
\hline & Mean & Standard deviation & Number of observations \\
\hline Beta & 1.137 & 0.662 & 214 \\
\hline Risk premium & 0.099 & 0.034 & 214 \\
\hline Risk free rate & 0.041 & 0.018 & 214 \\
\hline Cost of equity capital & 0.154 & 0.081 & 214 \\
\hline Intrinsic value of a share of stock (USD) & 0.436 & 12.220 & 214 \\
\hline Relative value (P/B) of a share of stock (USD) & 14.822 & 19.607 & 196 \\
\hline Relative value (P/S) of a share of stock (USD) & 13.602 & 15.661 & 206 \\
\hline Stock price (USD) & 13.794 & 15.983 & 214
\end{tabular}

To assess the ability of estimated intrinsic and relative values to reflect market values, we first examine the distribution of valuation differences which are defined as follows:

$$
\varepsilon_{i t}=\frac{\hat{P}_{i t}-P_{i t}}{P_{i t}}
$$

Where:

$\varepsilon_{i t}$ : valuation difference for stock i at time $\mathrm{t}$

$\hat{P}_{i t}$ : estimated value of stock $\mathrm{i}$ at time $\mathrm{t}$

$P_{i t}$ : price of stock i at time t (valuation date - three months after the financial year end).

Table 4. Valuation differences

\begin{tabular}{|c|c|c|c|c|}
\hline & & Mean of differences & Mean of absolute differences & Number of observations \\
\hline Eundomentol voluo & & $-1.705 * * *$ & 1000 & 214 \\
\hline гundamental valua & & $(-6.250)$ & 1.780 & 214 \\
\hline & $\mathrm{D} / \mathrm{P}$ & $0.658 * * *$ & 1228 & 106 \\
\hline & F/D & $(4.168)$ & 1.220 & 190 \\
\hline Rratre vatuation & & $0.334 * * *$ & & \\
\hline & $\mathrm{P} / \mathrm{S}$ & $(3.736)$ & 0.805 & 206 \\
\hline
\end{tabular}

Table 4 presents descriptive statistics of valuation differences and tests whether the average difference is significantly different from zero. The mean difference shows the valuation bias while the average absolute difference measures the degree of precision (Note 2).

For fundamental valuation, the table shows that valuation differences are important. The mean difference is $-170 \%$ and is significantly different from zero. The fundamental valuation therefore gives an average value much lower than the market value. The mean differences in the case of valuation based on multiples of book value and sales are respectively $65 \%$ and $33 \%$. They are all significantly different from zero. Values given by the relative valuation are in average higher than market values and differences seem smallest for the multiple of sales. We check this result by performing a statistical comparison of absolute differences. Since these differences may not follow a normal distribution, we use the nonparametric Wilcoxon-Mann-Whitney test. 
Table 5. Wilcoxon-Mann-Whitney nonparametric tests

\begin{tabular}{llll}
\hline Mean absolute difference & Number of observations & Total ranks & Wilcoxon-Mann-Whitney test \\
\hline$\mu_{\varepsilon_{I V}}=1.990$ & 214 & 52714 & $Z=7.289$ \\
\hline$\mu_{\varepsilon_{P B}}=1.228$ & 196 & 31541 & $p=0.000$ \\
\hline$\mu_{\varepsilon_{I V}}=1.990$ & 214 & 57503 & $Z=10.016$ \\
\hline$\mu_{\varepsilon_{P S}}=0.805$ & 206 & 30907 & $p=0.000$ \\
\hline$\mu_{\varepsilon_{P S}}=0.805$ & 206 & 37792 & $Z=-3.192$ \\
\hline$\mu_{\varepsilon_{P B}}=1.228$ & 196 & 43211 & $p=0.000$ \\
\hline
\end{tabular}

Table 5 presents the results of these tests. It indicates that all mean absolute differences are significantly different. Their values show that, on average, the relative valuation using multiples of sales gives estimates closest to market values. The multiple of book value ranks second and finally, estimates from the fundamental valuation are furthest from market values.

A model can help to better estimate values in average but it is also possible that it poorly explains their variation. Therefore, we supplement the above tests by examining the ability of the estimates given by different approaches to explain changes in market values. The following regression is tested to examine the relationship between estimated values and market values.

Where:

$$
P_{i t}=\alpha+\beta \times \hat{P}_{i t}+u_{i t}
$$

$\hat{P}_{i t}$ : estimated value of the firm i's share of stock at $\mathrm{t}$

$P_{i t}$ : stock price of firm i at $\mathrm{t}$ (three months after financial year end)

$u_{i t}:$ error term

Table 6. Regression estimation results

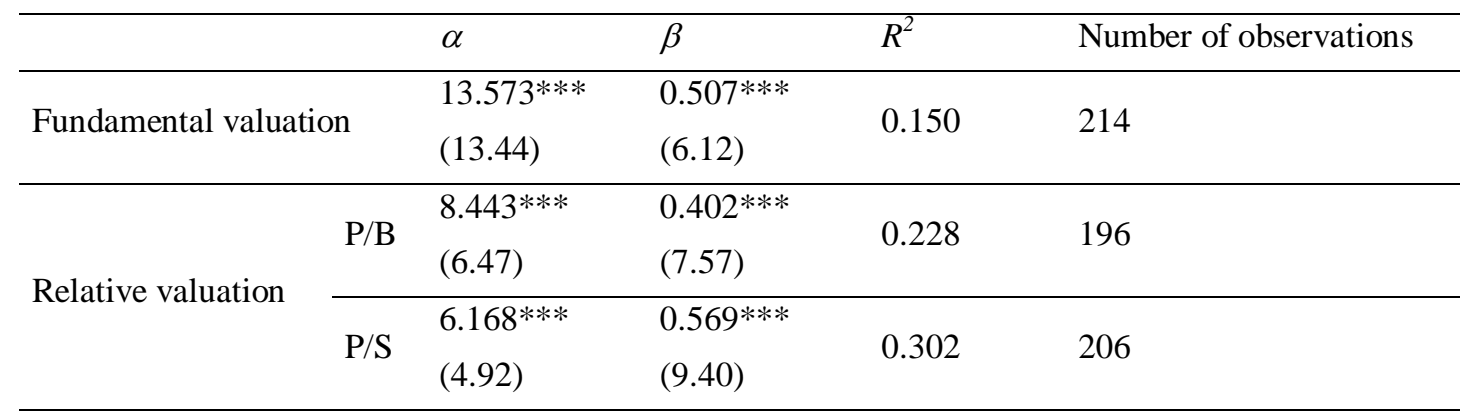

Table 6 shows that main results from the above mean comparison tests are confirmed. In terms of explanatory power, the relative method based on multiples of sales give estimates explaining approximately $30 \%$ of variations in market values (30\%) and ranks first. The method based on multiples of book value ranks second with a $\mathrm{R}^{2}$ of $23 \%$ whereas estimated intrinsic values explain only $15 \%$ of changes in market values. It seems that a simple multiple of sales (which have little theoretical connection with the firm value) is sufficient to give estimates which better reflect market values than a theoretically more sophisticated valuation model.

\section{Robustness Tests}

First, we check if estimates of fundamental values from the residual income model are sensitive to changes in the cost of equity capital. We change this cost respectively by $-50 \%,-40 \%,-30 \%,-20 \%,-10 \%, 10 \%, 20 \%, 30 \%, 40 \%$ and 50\%, then estimate intrinsic values for these cases and compare with relative values. In all cases, estimated intrinsic values are still furthest from market values and their explanatory power is still the lowest compared to estimated relative values. Next, we examine the sensitivity of estimated intrinsic values to assumptions about the perpetual abnormal return in the model's terminal value. However, instead of computing one intrinsic value for each hypothetical abnormal return, we determine its value implied from the equation (3), namely, that which equalizes the intrinsic value and the market value of a share of stock. Specifically, from (3): 


$$
R O E_{t+n}-k_{e}=\frac{\left[P_{t}-b_{t}-\sum_{i=1}^{n-1} \frac{\left(R O E_{t+i}-k_{e}\right)}{\left(1+k_{e}\right)^{i}} \times b_{t+i-1}\right] \times\left(1+k_{e}\right)^{n-1} \times k_{e}}{b_{t+n-1}}
$$

Descriptive statistics for the abnormal return's implied values are summarized in Table 7. For estimated intrinsic values to be equal to market values, the perpetual abnormal return from the fourth year on must average $274 \%$ ! For the median firm in the sample, this value is $96 \%$ ! For a sample of over 200 observations, these figures prove unrealistic. It seems that estimated fundamental values fail to be reflected by market values of biotech firms if realistic assumptions about the cost of capital and expected abnormal returns are maintained.

Table 7. Implied abnormal return

\begin{tabular}{llllll}
\hline & Mean & Median & Minimum & Maximum & Number of observations \\
\hline Implied abnormal return & 2.744 & 0.964 & 0.019 & 38.199 & 204 \\
\hline
\end{tabular}

Finally, we verify if the relation between estimated values and market values is influenced by the study period (before or after the fall of high-tech values in Spring 2000). Instead of dividing the sample and estimating the relation for each of the subsamples, the interactive effect of estimated value and study period on market value for the whole sample is modeled and tested. In other words, the independent variable's coefficient is allowed to vary depending on whether the period is before or after the fall of high-tech values. For that purpose, the following model is considered:

$$
P_{i t}=\alpha+\beta \times \hat{P}_{i t}+\delta \times \hat{P}_{i t} \times \text { Period }+\gamma \times \text { Period }+u_{i t}
$$

Where Period is a dummy variable that taking the value 0 when the observation belongs to the period before the fall of 2000 and 1 otherwise.

\begin{tabular}{|c|c|c|c|c|c|c|c|}
\hline & & $\alpha$ & $\beta$ & $\delta$ & $\gamma$ & $R^{2}$ & Number of observations \\
\hline \multirow{2}{*}{\multicolumn{2}{|c|}{ Fundamental valuation }} & $9.747 * * *$ & $0.612 * * *$ & $-0.192^{\mathrm{ns}}$ & $7.910 * * *$ & \multirow{2}{*}{0.216} & \multirow{2}{*}{214} \\
\hline & & $(7.17)$ & $(4.93)$ & $(-1.18)$ & $(4.05)$ & & \\
\hline \multirow{4}{*}{ Relative valuation } & $\mathrm{D} / \mathrm{D}$ & $5.088^{* * *}$ & $0.502 * * *$ & $-0.157^{\mathrm{ns}}$ & $6.993 * *$ & \multirow{2}{*}{0.255} & \multirow{2}{*}{196} \\
\hline & P/B & $(2.55)$ & $(3.63)$ & $(-1.05)$ & $(2.55)$ & & \\
\hline & \multirow{2}{*}{$\mathrm{P} / \mathrm{S}$} & $2.683^{*}$ & $0.741 * * *$ & $-0.369 * * *$ & $9.080 * * *$ & \multirow{2}{*}{0.347} & \multirow{2}{*}{206} \\
\hline & & $(1.73)$ & $(8.05)$ & $(-3.00)$ & $(3.60)$ & & \\
\hline
\end{tabular}

Table 8 . Test results for the interactive term

The results are presented in Table 8 . The coefficient $\delta$ of the interaction term $\hat{P}_{i t} \times$ Period is not significantly different from zero in cases of intrinsic values and relative values based on P/B. The relationship between market values and estimated values do not appear to depend on the study period. However, when estimated values are based on the multiple of sales that have little theoretical connection with firm value, the interaction term's coefficient is significantly negative. This means that a variation in the relative valuation based on sales results in less variation in market value after the fall than before it. After the high-tech bubble, the stock market seems less irrational with regard to the multiple of sales but it still fails to better reflect firm intrinsic values and the market valuation still seems more based on relative values.

\section{Conclusion}

We complete the literature on firm valuation by exploiting the conceptual difference between the intrinsic and relative values. The intrinsic value is derived from a fundamental valuation model with information on theoretical determinants of firm value while the relative value reflecting market trends is based on market valuation of comparable firms. Comparing these two values for a sample of U.S. biotechnology firms allows us to draw the following conclusions. The relative valuation provides estimates much closer to market values than the fundamental 
valuation. In particular, a simple multiple of sales (which have little theoretical connection with firm value) is sufficient to give estimates which are better reflected by the stock market value than a theoretically more sophisticated valuation model. Robustness tests show that these results are not sensitive to changes in cost of equity capital and perpetual abnormal return on equity. It seems that the estimated fundamental value of biotech firms fails to be reflected by the market under realistic assumptions of the model. Their market valuation is rather based on relative value for both periods before and after the fall of high-tech stocks.

Our study has several limitations that can open up avenues for further tests on the topic. First, in order to measure intrinsic value, especially for high-tech firms, models and approaches other than valuation based on residual income need to be examined and compared. Second, the comparison between intrinsic and relative values should be made for other periods and countries with larger samples. In addition, future research may focus on how the intrinsic value of high-tech firms can be better reflected by the financial markets.

\section{Acknowledgements}

This research is a product of the Research Group on Corporate Governance and Financial Markets at Foreign Trade University, Hanoi, Vietnam.

\section{References}

Alford, A. W. (1992). The effect of the set of comparable firms on the accuracy of the price-earnings valuation method. Journal of Accounting Research, 30(1), 94. https://doi.org/10.2307/2491093

Brown, L. D., \& Rozeff, M. S. (1978). The superiority of analyst forecasts as measures of expectations: evidence from earnings. The Journal of Finance, 33(1), 1. https://doi.org/10.2307/2326346

Brown, L. D., Hagerman, R. L., Griffin, P. A., \& Zmijewski, M. E. (1987a). Security analyst superiority relative to univariate time-series models in forecasting quarterly earnings. Journal of Accounting and Economics, 9(1), 61-87. https://doi.org/10.1016/0165-4101(87)90017-6

Brown, L. D., Hagerman, R. L., Griffin, P. A., \& Zmijewski, M. E. (1987b). An evaluation of alternative proxies for the market's assessment of unexpected earnings. Journal of Accounting and Economics, 9(2), 159-193. https://doi.org/10.1016/0165-4101(87)90004-8

Collins, W. A., \& Hopwood, W. S. (1980). A multivariate analysis of annual earnings forecasts generated from quarterly forecasts of financial analysts and univariate time-series models. Journal of Accounting Research, 18(2), 390. https://doi.org/10.2307/2490585

Damodaran, A. (2001). The dark side of valuation: valuing old tech, new tech and new economy companies. Prentice Hall.

Dechow, P. M., Hutton, A. P., \& Sloan, R. G. (1999). An empirical assessment of the residual income valuation model. Journal of Accounting and Economics, 26(1-3), 1-34. https://doi.org/10.1016/S0165-4101(98)00049-4

Eberhart, A. C. (2001). Comparable firms and the precision of equity valuations. Journal of Banking and Finance, 25(7), 1367-1400. https://doi.org/10.1016/S0378-4266(01)00171-6

Ely, K., Simko, P. J., \& Thomas, L. G. (2003). The usefulness of biotechnology firms' drug development status in the evaluation of research and development costs. Journal of Accounting, Auditing \& Finance, 18(1), 163-196. https://doi.org/10.1177/0148558X0301800109

Frankel, R. M., \& Lee, C. M. C. (1996). Accounting diversity and international valuation. Retrieved from https://papers.ssrn.com/abstract=2658

Frankel, R., \& Lee, C. M. C. (1998). Accounting valuation, market expectation, and cross-sectional stock returns. Journal of Accounting and Economics, 25(3), 283-319. https://doi.org/10.1016/S0165-4101(98)00026-3

Fried, D., \& Givoly, D. (1982). Financial analysts' forecasts of earnings. A better surrogate for market expectations. Journal of Accounting and Economics, 4(2), 85-107. https://doi.org/10.1016/0165-4101(82)90015-5

Gilson, S. C., Hotchkiss, E. S., \& Ruback, R. S. (2000). Valuation of Bankrupt Firms. Review of Financial Studies, 13(1), 43-74. Retrieved from https://ideas.repec.org/a/oup/rfinst/v13y2000i1p43-74.html

Higgins, H. N. (2011). Forecasting stock price with the residual income model. Review of Quantitative Finance and Accounting, 36(4), 583-604. https://doi.org/10.1007/s11156-010-0187-y

Huberman, G., \& Regev, T. (2001). Contagious speculation and a cure for cancer: A nonevent that made stock prices soar. Journal of Finance, 56(1), 387-396. https://doi.org/10.1111/0022-1082.00330 
Jorgensen, B. N., Lee, Y. G., \& Yoo, Y. K. (2011). The valuation accuracy of equity value estimates inferred from conventional empirical implementations of the abnormal earnings growth model: US evidence. Journal of Business Finance \& Accounting, 38(3-4), 446-471. https://doi.org/10.1111/j.1468-5957.2011.02241.x

Kaplan, S. N., \& Ruback, R. S. (1995). The valuation of cash flow forecasts: an empirical analysis. The Journal of Finance, 50(4), 1059. https://doi.org/10.2307/2329344

Kim, M., \& Ritter, J. R. (1999). Valuing IPOs. Journal of Financial Economics, 53(3), 409-437. https://doi.org/10.1016/S0304-405X(99)00027-6

Kuo, C. Y. (2017). Is the accuracy of stock value forecasting relevant to industry factors or firm-specific factors? An empirical study of the Ohlson model. Review of Quantitative Finance and Accounting, 49(1), 195-225. https://doi.org/10.1007/s11156-016-0587-8

Lang, L. H. P., \& Stulz, R. M. (1992). Contagion and competitive intra-industry effects of bankruptcy announcements, an empirical analysis. Journal of Financial Economics, 32(1), 45-60. https://doi.org/10.1016/0304-405X(92)90024-R

Lee, C. M. C., \& Swaminathan, B. (1999). Valuing the dow: a bottom-up approach. Financial Analysts Journal, 55(5), 4-23. https://doi.org/10.2469/faj.v55.n5.2295

Lee, C. M. C., Myers, J., \& Swaminathan, B. (1999). What is the intrinsic value of the dow?. Journal of Finance, 54(5), 1693-1741. https://doi.org/10.1111/0022-1082.00164

Lee, S. C., Lin, C. T., \& Yu, M. T. (2013). A fractional cointegration approach to testing the Ohlson accounting based valuation model. Review of Quantitative Finance and Accounting, 41(3), 535-547. https://doi.org/10.1007/s11156-012-0321-0

Lie, E., \& Lie, H. J. (2002). Multiples Used to Estimate Corporate Value. Financial Analysts Journal, 58(2), 44-54. https://doi.org/10.2469/faj.v58.n2.2522

Liu, J., Nissim, D., \& Thomas, J. (2002). Equity valuation using multiples. Journal of Accounting Research, 40(1), 135-172. https://doi.org/10.1111/1475-679X.00042

Ohlson, J. A. (1995). Earnings, book values, and dividends in equity valuation. Contemporary Accounting Research, 11(2), 661-687. https://doi.org/10.1111/j.1911-3846.1995.tb00461.x

Ohlson, J. A., \& Juettner-Nauroth, B. E. (2005). Expected EPS and EPS growth as determinantsof value. Review of Accounting Studies, 10(2-3), 349-365. https://doi.org/10.1007/s11142-005-1535-3

Penman, S. H., \& Sougiannis, T. (1998). A comparison of dividend, cash flow, and earnings approaches to equity valuation. Contemporary Accounting Research, 15(3), 343-383. https://doi.org/10.1111/j.1911-3846.1998.tb00564.x

Wells, P. A., Bailey, P., Brown, P., \& Potter, M. (2008). A practical comparison of firm valuation models: cash flow, dividend and income. JASSA: The Finsia Journal of Applied Finance, 2, 22-28.

\section{Notes}

Note 1. See Brown \& Rozeff (1978), Collins \& Hopwood (1980), Fried \& Givoly (1982) and Brown et al. (1987a,b).

Note 2. In this study, a valuation is considered as accurate if estimated values are close to market values. However, this does not mean that market valuation is regarded as correct.

\section{Copyrights}

Copyright for this article is retained by the author(s), with first publication rights granted to the journal.

This is an open-access article distributed under the terms and conditions of the Creative Commons Attribution license (http://creativecommons.org/licenses/by/4.0/). 